\title{
REDES SOCIAIS NA INTERNET: AMBIENTE PESSOAL DE APRENDIZAGEM NA FORMAÇÃO DE PROFESSORES INICIANTES DE MATEMÁTICA
}

Gilmara Teixeira Barcelos, PGIE/UFRGS, IF Fluminense Campus Campos-Centro

gilmarab@iff.edu.br

Liliana Maria Passerino, PGIE/UFRGS

liliana@cinted.ufrgs.br

Patricia Alejandra Behar, NUTED-PGIE/UFRGS

patricia.behar@ufrgs.br

\section{RESUMO}

A formação de professores requer participação, interações, troca de experiências, cooperação, consideração do contexto e dos saberes docentes. Nesse sentido, as Redes Sociais na Internet (RSI), enquanto um Personal Learning Environment - PLE (Ambiente Pessoal de Aprendizagem) tem grande potencial para apoiar o processo de formação. Essas redes, geralmente, usadas para conhecer pessoas, compartilhar fotos, vídeos e comentários podem também, representar um importante recurso de apoio à formação continuada de professores presenciais ou não. Nesta perspectiva, apresenta-se a formação T-PROIM (Tecnologias na Prática docente de pROfessores Iniciantes de Matemática) vivenciada com professores iniciantes de Matemática com o apoio de uma RSI. Essa visa a contribuir para integração das tecnologias digitais à prática docente de professores. No presente artigo, discutem-se a formação de professores, as RSI e o PLE, descrevem-se a formação T-PROIM, a plataforma Elgg e a rede social que apoia a formação. Além disso, apresentam-se os caminhos metodológicos da pesquisa e a análise preliminar da formação. Finalizando, tecem-se algumas considerações sobre a formação e apresentam-se formas de continuidades do estudo realizado.

Palavras-chave: Formação de professores, Tecnologias, Redes Sociais na Internet.

\section{INTERNET SOCIAL NETWORKS AS PERSONAL LEARNING} ENVIRONMENTS FOR MATH EDUCATION STUDENTS

\section{ABSTRACT}

Teacher Education requires participation, interaction, experience exchange, cooperation, and attention to teaching contexts and knowledge. As Personal Learning Environments (PLE), Internet Social Networks (ISN) have great potential to support continuing education of teachers. These networks, mostly used to meet people, share photos, videos and comments, can also be a relevant resource to support continuing education whether in the classroom or on line. This paper presents an experiment of continuing education with beginning teachers of Math with the support of an ISN. The aim is contributing to the integration of digital technologies into teachers' practice. Thus, the study presents an overview of teaching education called T-PROIM, ISNs, and PLEs, as well as a description of a proposal for continuing education, the Elgg platform and its network as supporting educational tool. It also presents the methodology of the research and a preliminary analysis of the project. The paper closes with considerations on this ongoing educational program, and its possibilities for future developments.

Key-Words: Teacher Education, Technologies, Internet Social Networks .

\section{Introdução}

O professor, entre outras funções é o responsável por estabelecer o ambiente e preparar oportunidades de aprendizagem que facilitem o uso das tecnologias pelo aluno, para fins pedagógicos (Unesco, 2009). Algumas pesquisas têm sido realizadas, visando 
a investigar o uso das Tecnologias Digitais (TD) nas aulas (FVC, 2009; Linckels et al., 2009). A análise destas pesquisas ressalta a importância da preparação dos professores, para que possam integrar as referidas tecnologias em suas práticas docentes. Além disso, ratifica a importância da criação de novas propostas de formação inicial e continuada para integração das TD no processo de ensino e aprendizagem. Considera-se que essas propostas, entre outros aspectos, deveriam contemplar o uso pedagógico da TD na construção de conhecimentos dos conteúdos que compõem a matriz curricular.

Além disso, a formação de professores requer participação, interações, troca de experiências, cooperação, consideração do contexto e dos saberes docentes (Tardif, 2007). Nesse sentido, as Redes Sociais na Internet (RSI), enquanto um Personal Learning Environment - PLE (Ambiente Pessoal de Aprendizagem) tem grande potencial para apoiar o processo de formação de professores. Geralmente, as RSI são usadas para conhecer pessoas, disponibilizar fotos, vídeos, comentários, comercializar produto (Clark e Roberts, 2010). Porém, também podem representar um importante recurso de apoio às atividades educacionais presenciais ou não.

Segundo José Armando Valente ${ }^{1}$ (Klix, 2011), o uso das RSI, para fins educacionais tem ocorrido em iniciativas pontuais como, por exemplo, o uso de blogs e outros recursos das RSI em aula, mas, geralmente por interesse particular de alguns profissionais. Além disso, destaca que, na maioria dos casos, o uso é para divulgar algum conteúdo que não tenha sido possível de apresentar no momento da aula e para receber material de aluno. Segundo Valente, essas ações não são inovadoras, apenas contribuem para transmissão de informação. Não se questiona o valor desses usos, mas considera-se que é possível ir além, criando laços fortes num movimento dinâmico.

Nesse contexto, o objetivo deste artigo é apresentar uma análise preliminar da formação T-PROIM (Tecnologias na Prática docente de pROfessores Iniciantes de Matemática). Essa é apoiada por uma $\mathrm{RSI}^{2}$ enquanto um PLE e visa a contribuir para a integração de TD à prática docente de professores iniciantes de Matemática.

\section{Formação de professores: RSI e PLE}

Os padrões de competência em tecnologias de informação e comunicação para professores (Unesco, 2009) ressaltam que as mudanças na prática pedagógica devem envolver o uso de diversas tecnologias, ferramentas e conteúdo eletrônico. Destaca-se, ainda, que é importante saber onde e quando usar (ou não) as tecnologias. Para tanto, é relevante que professores sejam preparados para estas novas práticas, afinal desempenham papel de destaque na integração da escola à cultura digital.

Nesse contexto, surge a questão: As RSI estão presentes nos mais variados contextos com finalidades diversas, por que não as inserir na formação de professores para uso pedagógico das TD? Defende-se que essas redes podem auxiliar programas de formação de professores, possibilitando que esses vivenciem as vantagens das funcionalidades e assim as usem com seus alunos (Barcelos, Passerino e Behar, 2010).

Para a criação de RSI, faz-se necessário o uso de plataformas como, por exemplo: Orkut, Facebook, Ning, SocialGO, Meezoog, WackWall, Grouply, Peabirus, Elgg, entre outras. Essas plataformas não são as RSI, mas as representam (Recuero, 2009), as redes em si são criadas a partir das interações, dos laços sociais estabelecidos e do capital social gerado. Plataformas também são denominadas ferramentas, sistemas, sites ou softwares. Algumas RSI podem ser usadas como um PLE.

O conceito de PLE é amplamente discutido na literatura. Há uma diversidade de perspectivas e enfoques do que seja PLE (Mota, 2009, Milligan et al., 2006). Wilson (2005) usou a expressão "Futuro VLE" antes de usar a expressão PLE, este autor é considerado o pioneiro no estudo e caracterização do PLE. Segundo Attwell (2007), somente em um aspecto muitos autores concordam quanto ao PLE, não é um software e, 
sim, uma nova abordagem que usa tecnologias para a aprendizagem. Os PLEs (Personal Learning Environments) representam para a educação, os princípios do e-Learning 2.0, do poder e autonomia do utilizador, da abertura, da colaboração e da partilha, da aprendizagem permanente e ao longo da vida, da importância e valor da aprendizagem informal, das potencialidades dos softwares sociais, da rede como espaço de socialização, de conhecimento e de aprendizagem (Attwell, 2007; Mota, 2009). A ideia de um PLE sustenta que a aprendizagem ocorre em diferentes contextos e situações, ampliando assim, o acesso à educação, por meio da possibilidade de inter-relacionar a aprendizagem da vida e a aprendizagem da escola ou da universidade (Attwell, 2007). Além disso, um PLE fornece mais responsabilidade e mais independência aos alunos (usuários)."Num Personal Learning Environment, o aprendente utilizará um conjunto único de ferramentas, personalizado de acordo com as suas preferências e necessidades [...]" (Mota, 2009, p.14). Segundo Mota (2009), a plataforma Elgg pode ser considerada um PLE, visualizando-a como um conjunto de ferramentas integradas (blog, perfil, rss, permissões, grupos, etc.) com grande controle por parte do utilizador.

Os PLEs, segundo Milligan et al. (2006), apresentam características mais inovadoras que os sistemas de gestão da aprendizagem (Learning Management Systems - LMSs) e que os ambientes virtuais de aprendizagem (Virtual Learning Environments - VLEs). Esses ainda estão próximos da metáfora da sala de aula, neles os alunos vivenciam a mesma experiência, veem o mesmo conteúdo, organizado da mesma forma e com as mesmas ferramentas. Segundo Attwell (2010), os LMSs e os VLEs têm se preocupado em espelhar a organização tradicional da educação e melhorar a gestão da educação em vez de apoiar a aprendizagem. Nos LMSs e nos VLEs encontram-se alguns recursos tais como, wiki ou podcast, porém ainda dependem de decisões e controle dos administradores e/ou professores. A maior parte dos autores que analisam e comparam LMSs/VLEs e os PLEs, porém, buscam a articulação entre os mesmos (Mota, 2009), integrando-os.

\section{Caminhos metodológicos: formação continuada e rede social}

A formação T-PROIM considera a formação inicial dos participantes, criando um elo entre a universidade e sala aula, para além dos estágios supervisionados. Essa formação, a partir da utilização de uma RSI na plataforma Elgg, apoia e orienta os professores em momentos presenciais e não presenciais de forma a garantir maior participação. As atividades propostas estão sendo realizadas considerando o contexto da sala de aula de cada professor, tentando assim minimizar o problema da não aplicação do que é estudado nos programas de formação continuada, nas atividades docentes.

O público alvo é composto por egressos da licenciatura em Matemática de um Instituto Federal, que estejam iniciando suas práticas docentes (professores iniciantes). A formação é na modalidade blended learning. Segundo Graham (2005), esta modalidade é uma combinação de aprendizagem presencial com aprendizagem virtual interativa, ou seja, uma mistura de modalidades sob demanda. O período estabelecido para ocorrer a formação T-PROIM fundamenta-se no fato de que as bases dos saberes profissionais, geralmente, são construídas no início da carreira (Tardif, 2007). Além de ser o início uma fase crítica, muitas vezes decorrente do confronto inicial com a dura e complexa realidade do exercício da profissão (Tardif, 2007).

Os objetivos da proposta de formação T-PROIM são: i) fundamentar a utilização das TD nas escolas nas quais os professores/participantes atuam; ii) considerar o contexto do professor nas atividades; iii) criar espaço de criação de recursos pedagógicos e de publicação dos mesmos; iv) proporcionar momentos de formação entre pares.

O processo de formação foi elaborado a partir da concepção epistemológica sóciohistórica e por esse motivo considera as interações interpessoais como etapa essencial 
para a internalização dos processos psicológicos superiores (Vygotsky, 2007). Além disso, considera as relações existentes entre formação inicial, contexto social, história pessoal, saberes docentes, TD e prática docente (Imbernón, 2010).

A T-PROIM foi estruturada em três grandes fases. Na primeira fase, denominada "Inicial", de maneira geral, foram realizados: um diagnóstico do contexto de trabalho dos professores; uma sondagem das estratégias usadas habitualmente durante as aulas dos mesmos; estudos e pesquisas sobre TD na aprendizagem Matemática e a elaboração/seleção/adaptação de recursos pedagógicos (applets, unidades de aprendizagem, atividades que utilizem TD para o estudo de temas matemáticos, entre outros). Na segunda fase, denominada "Desenvolvimento", os professores participantes, aplicaram (e aplicarão) em suas turmas o que foi planejado na etapa anterior. Na terceira e última fase, denominada "Análise" é feita uma avaliação da segunda fase de forma compartilhada e presencial, ou seja, refletir coletivamente suas experiências. Essas fases ocorrem a cada conteúdo que os professores optam por usar tecnologias.

Os aspectos que diferem essa proposta de formação continuada de outras analisadas (Costa, 2008; Brasil, 2007; Vosgerau et al., 2007) são: i) o publico alvo (professores iniciantes); ii) o momento em que a formação continuada acontecerá (início na carreira docente); iii) o uso de uma RSI como suporte para as interações (Barcelos, Passerino e Behar, 2010). As atividades da formação T-PROIM foram iniciadas em março de 2011 e se estenderão até setembro de 2011. Como o contexto social e as interações são as bases dessa formação, o planejamento inicial foi elaborado com grande flexibilidade, ou seja, as atividades realizadas a cada encontro presencial ou não é que direcionam as atividades futuras. Inicialmente, foram planejados dez encontros presenciais com duração de três horas cada um. A formação T-PROIM é um sistema de premissas teóricas e práticas que representa, explica e orienta professores iniciantes de Matemática a usar pedagogicamente as TD nas suas práticas docentes. Participam oito professores de Matemática da rede pública de ensino ${ }^{4}$.

Quadro 1: Descrição das atividades

\begin{tabular}{|c|c|l|}
\hline & Data & \multicolumn{1}{c|}{ Temas/Ações } \\
\hline $\mathbf{1}^{\mathbf{0}}$ Encontro & $17 / 03$ & $\begin{array}{l}\text { Descrição da proposta da formação continuada. } \\
\text { Questionário de sondagem. } \\
\text { Apresentação de pesquisas que descrevem o contexto das escolas quanto às } \\
\text { tecnologias digitais. } \\
\text { Apresentação e experimentação de ferramentas da RSI. }\end{array}$ \\
\hline $\mathbf{2}^{\mathbf{0}}$ Encontro & $31 / 03$ & $\begin{array}{l}\text { Descrição oral do contexto docente de cada professor. } \\
\text { Discussão das postagens da RSI. } \\
\text { Estudo dos recursos do br Office (writer e impress). } \\
\text { Apresentação e experimentação de ferramentas da RSI. }\end{array}$ \\
\hline $\mathbf{3}^{\mathbf{o}}$ Encontro & $14 / 04$ & $\begin{array}{l}\text { Discussão das postagens da RSI. } \\
\text { Tecnologias móveis no processo de ensino e aprendizagem de Matemática. } \\
\text { Experimentação de applets - Math 4 Mobile. }\end{array}$ \\
\hline $\mathbf{4}^{\mathbf{0}}$ Encontro & $28 / 04$ & $\begin{array}{l}\text { Apresentação e discussão dos trabalhos preparados no Impress } \\
\text { Investigação do portal "Tecnologias de Informação e Comunicação no } \\
\text { Processo de Ensino e Aprendizagem de Matemática". } \\
\text { Apresentação e experimentação do software photo story 37. }\end{array}$ \\
\hline $\mathbf{5}^{\mathbf{0}}$ Encontro & $12 / 05$ & $\begin{array}{l}\text { Destaque dos pontos importantes da palestra online. } \\
\text { Análise de vídeos educacionais. } \\
\text { Apresentação e discussão dos vídeos preparados no photo story } 3^{8} . \\
\text { Apresentação e experimentação dos softwares audacity, any converter e } \\
\text { vdownloader. }\end{array}$ \\
\hline
\end{tabular}

A pesquisa é de cunho qualitativo, por meio de um estudo de caso. O objetivo é analisar a influência da formação T-PROIM na prática docente dos professores participantes. Foram utilizadas as seguintes técnicas de coletas de dados: questionário, entrevista, observação, análise dos conteúdos postados na rede. Estão sendo observados 
os comportamentos, os questionamentos e as ações dos participantes ao longo da formação na RSI e nos encontros presenciais. Até a presente data (maio 2011) ocorreram cinco encontros presenciais (três horas cada), uma palestra online e muitas interações por meio da RSI. Como já mencionado, as atividades foram planejadas considerando o contexto dos professores assim como solicitações feitas pelos mesmos. O quadro 1 apresenta um resumo dos temas e ações realizadas. Em todos os encontros presenciais, textos relacionados aos temas em estudo foram discutidos.

Todos os oito professores (apenas um do sexo masculino), no primeiro encontro, responderam a um questionário. Com esse instrumento pretendeu-se reunir informação sobre a existência de TD nas escolas em que atuam assim como as condições dessas; a utilização de TD, enquanto recurso pedagógico na prática docente; a utilização de RSI em contextos diversos; a finalidade de uso das RSI. O questionário continha duas perguntas de identificação do inquirido e cinco perguntas de respostas fechadas, porém, em três delas havia espaço para comentários sobre a resposta assinalada.

Entre o $1^{\circ}$ e o $2^{\circ}$ encontro ocorreram as entrevistas em horários marcados, individualmente. $\mathrm{O}$ objetivo desse instrumento de coleta de dados foi captar particularidades do contexto de cada professor, além de investigar as estratégias já utilizadas, o interesse pelo uso pedagógico das TD e a infraestrutura das escolas.

A cada semana foi elaborado um relatório contendo a descrição e análise das atividades desenvolvidas, do que foi observado e, dos conteúdos postados na rede. Como a plataforma que suporta da RSI da formação T-PROIM é a Elgg, essa é apresentada, resumidamente, a seguir.

\section{A plataforma Elgg: virtual settlement para a rede social da formação T-PROIM}

Em geral redes sociais online são estruturadas a partir de um virtual settlement (JONES, 1997) ou suporte (Orkut, Facebook, MySpace, Elgg, Ning) por meio do qual inicia-se o processo de configuração da rede. Para uma ferramenta online ser considerada um virtual settlment segundo Jones (1997), precisa permitir ao menos quatro funcionalidades: i) nível mínimo de interatividade; ii) variedade de comunicadores; iii) um espaço público virtual em comum e iv) nível mínimo de associação sustentada. A plataforma $\mathrm{Elgg}^{3}$, criada em 2004, apresenta as características citadas. É um sistema livre, multiplataforma e tem por objetivo criar RSI.

A instalação da plataforma Elgg requer a instalação e configuração de servidores web e de email. No servidor web, pode-se utilizar o software Apache, com a linguagem de programação PHP e o sistema gerenciador de banco de dados MySQL (Elgg, 2010). Após a configuração do ambiente, conforme as especificações do Elgg, basta descompactar o arquivo do Elgg na pasta WWW do servidor Apache. A gratuidade, o idioma, a variedade de dispositivos e o domínio dos recursos disponibilizados nas plataformas são aspectos considerados importantes para o contexto educacional. Como esses aspectos são contemplados na plataforma Elgg, essa foi escolhida para a pesquisa.

Essa plataforma possibilita a instalação de diversos plugins, alguns são baixados no pacote padrão de instalação da Elgg (denominados plugins de funcionalidades) e outros são obtidos separadamente. Na versão 1.7.5, os plugins de funcionalidade são: Blog (blog), bookmarks (favoritos), file (arquivos), groups (grupos), external pages (páginas externas), message (mensagens na rede), pages (páginas), the wire (microblog- pequeno blog), twitter service (twitter), profile (perfil). A plataforma Elgg permite um grande controle dos recursos tanto por parte do administrador como dos demais usuários. É possível publicar, organizar e compartilhar materiais de trabalho e de suporte à aprendizagem. Essas características possibilitam utilizá-la como um PLE.

Todo usuário possui além de sua página inicial, uma página denominada perfil. Nessa, além de dados pessoais (perfil), é possível escolher quais as ferramentas bem 
como seus conteúdos, que aparecerão para os demais usuários da rede. Os conteúdos podem ser adicionados ou modificados tanto pela página inicial do usuário quanto pela página perfil, desde que estes apareceram nas duas. Cada usuário, assim como o administrador podem escolher para sua página pessoal, por meio do plugin "theme", a cor do menu superior, do fundo da tela e, além disso, pode inserir uma imagem na parte superior e, também pode repeti-la horizontal ou verticalmente. O conteúdo adicionado em arquivos, blog, wiki, álbum de fotos, calendário, entre outros disponíveis, na página pessoal ou na do perfil pode ser mostrado para o público de maneira geral, para usuários conectados, apenas para os amigos, ou até mesmo não ser mostrado (privado). Tais ações, assim como as já descritas retratam a autonomia do usuário no que é postado na RSI, fato positivo para o uso pedagógico da mesma. Na próxima seção, caracterizam-se os professores participantes da T-PROIM - usuários da RSI - assim como o contexto docente e, apresenta-se uma análise preliminar da formação, com foco na RSI.

\section{Formação continuada T-PROIM: uma análise preliminar}

Os dados levantados, por meio do questionário, foram tabulados e analisados. Os resultados considerados mais significativos são comentados a seguir. Designam-se por números os oito professores: $1,2,3,4,5,6,7$ e 8 . Todos atuam na rede pública de ensino, apenas a professora 7 atua em duas escolas, uma estadual e outra municipal ${ }^{9}$.

Em uma das escolas da professora 7 não há laboratório de informática e na escola da professora 3 o laboratório está desativado, a sala está sendo reformada ${ }^{10}$, em todas as demais escolas há laboratório de informática. Na percepção dos professores, as condições dos computadores de 37,5\% laboratórios foram consideradas "boas", $50 \%$ "regulares" e 12\% "péssimas". Dos oito laboratórios, três não têm acesso à Internet. Todos afirmaram que nunca usaram os laboratórios de informática com seus alunos.

Tabela 1: Finalidade de uso dos recursos tecnológicos

\begin{tabular}{|l|c|c|c|c|c|}
\hline $\begin{array}{l}\text { Funções } \\
\text { de } \\
\text { uso }\end{array}$ & $\begin{array}{c}\text { Processador } \\
\text { de } \\
\text { texto }\end{array}$ & $\begin{array}{c}\text { Planilhas } \\
\text { de } \\
\text { cálculo }\end{array}$ & $\begin{array}{c}\text { Softwares } \\
\text { educacionais }\end{array}$ & Internet & Outros \\
\hline Preparação de apostilas & $100 \%$ & $0 \%$ & $50 \%$ & $38 \%$ & $0 \%$ \\
\hline Preparação de aulas & $100 \%$ & $0 \%$ & $50 \%$ & $38 \%$ & $0 \%$ \\
\hline Preparação de provas & $100 \%$ & $0 \%$ & $38 \%$ & $38 \%$ & $0 \%$ \\
\hline $\begin{array}{l}\text { Durante as aulas para a } \\
\text { introdução dos conteúdos }\end{array}$ & $25 \%$ & $0 \%$ & $13 \%$ & $25 \%$ & $0 \%$ \\
\hline $\begin{array}{l}\text { Durante as aulas para } \\
\text { construção do conhecimento } \\
\text { (desenvolvimento da aula). }\end{array}$ & $13 \%$ & $0 \%$ & $25 \%$ & $25 \%$ & $0 \%$ \\
\hline $\begin{array}{l}\text { Durante as aulas para fixação } \\
\text { do conteúdo. }\end{array}$ & $25 \%$ & $0 \%$ & $13 \%$ & $13 \%$ & $0 \%$ \\
\hline Para atividade extraclasse. & $13 \%$ & $13 \%$ & $13 \%$ & $25 \%$ & $0 \%$ \\
\hline
\end{tabular}

Quanto à utilização de TD, enquanto recurso pedagógico na prática docente, todos afirmaram que usam. Foi solicitado que marcassem, numa lista de quatro itens, quais tecnologias usadas. Vale ressaltar que havia um quinto item denominado "outros". Nesse, o professor poderia citar outras tecnologias usadas. Todos afirmaram usar processadores de texto, $13 \%$ planilhas eletrônicas, 50\% software educacionais, $50 \%$ Internet e ninguém marcou o item "outros". Para identificar a finalidade do uso das TD, foi apresentado um quadro, no qual os professores deveriam assinalar as funções do uso. A tabela 1 apresenta o uso das tecnologias, apresentadas na primeira linha, nas funções listadas na primeira coluna da mesma.

Analisando os índices da tabela 1, verificou-se que tanto na preparação de apostilas como na preparação das aulas os recursos mais utilizados foram os processadores de texto, seguidos dos softwares educacionais e da Internet. Analisando as respostas dos 
questionários, percebeu-se que ocorreram erros ao marcar as finalidades de uso "durante as aulas para introdução dos conteúdos", "durante as aulas para construção do conhecimento (desenvolvimento da aula)", "durante as aulas para fixação do conteúdo", pois todos afirmaram, em outra questão, que nunca utilizaram tecnologias em suas aulas. Para investigar o motivo do erro, na entrevista foi questionado o motivo de terem assinalados os referidos itens. Todos responderam que a resposta foi dada considerando a preparação da aula. Esse fato ressalta a importância do uso de mais de um instrumento de coleta de dados.

Quando questionados sobre a fonte de conhecimento das tecnologias que utilizam na prática docente, as mais citadas foram cursos/oficinas (100\%), formação inicial (100\%), Internet $(25 \%)$ e colegas $(25 \%)$. Esses índices ressaltam a importância da formação inicial para o uso das TD na prática docente, mesmo que nesse contexto tenha refletido apenas em atividades de preparação das atividades a serem desenvolvidas nas aulas.

Seis professores haviam preparado o planejamento anual e desses, três contemplaram o uso de TD. Essa informação sinaliza interesse pelas tecnologias, característica considerada importante para o uso pedagógico das mesmas.

Como uma rede social seria usada para apoiar a formação T-PROIM, foi questionado se os professores usavam RSI em outros contextos e com qual finalidade. Cinco afirmaram que usam o Orkut, apenas um deles citou também o Twitter. As finalidades listadas por todos foram fazer amigos e compartilhar fotos. Três afirmaram que usam para interagir com alunos e colegas de profissão. Na entrevista, foi investigado como ocorre esta interação. A informação obtida foi que usam as comunidades do Orkut para interagir com outros professores e enviam mensagens, também pela referida plataforma, para ex-colegas de turma visando a esclarecer dúvidas e trocar materiais.

Por meio das entrevistas foi possível captar outras informações consideradas significativas para o planejamento das atividades da T-PROIM. Apenas a professora 4 não possui Internet em casa, porém essa afirmou que usa lan house, frequentemente. $O$ sistema operacional das escolas em que os professores atuam é o Linux. Todas as escolas possuem um profissional de apoio nos laboratórios. A função desse profissional é instalar softwares solicitados pelos professores e ajudar aos alunos a usarem os computadores durante as aulas. Nas escolas, não há coordenador de Matemática, apenas coordenador pedagógico, porém esse não interfere nas ações de sala de aula (de maneira geral, organizam horários e cobram a elaboração dos planejamentos). As estratégias usadas em sala de aula são aulas expositivas, trabalhos em grupo e folha de exercícios.

Todos afirmaram que, ao chegarem às escolas, sentiram-se perdidos, as orientações são superficiais e as situações vivenciadas são inéditas. Nesse sentido, todos consideraram que o apoio de um professor mais experiente no início da prática docente é muito importante. A professora 8 afirmou que tem recorrido a uma ex-professora da licenciatura para esclarecer dúvidas e solicitar sugestões para preparação de suas aulas. Quanto à formação inicial para o uso das TD, todos afirmaram que os conhecimentos construídos foram muito importantes para prática docente. Usam essas tecnologias na preparação das aulas, justificaram o não uso durante as aulas ao fato de o período letivo estar no início e a falta de infraestrutura das escolas.

No primeiro encontro presencial, ocorreu a apresentação dos recursos da RSI. Foi possível observar o encantamento dos professores pelas possibilidades da rede configurada para a formação. Também foram experimentadas as ferramentas microblogs, blogs, arquivos, amigos e o recurso que possibilita customizar as páginas. As demais ferramentas e funcionalidades foram comentadas no segundo encontro. Todos os professores experimentaram os recursos com facilidade, até mesmo os que 
nunca haviam usado outras redes sociais. Após a experimentação, o professor 2 afirmou que conhecia e já havia usado o Moodle, porém na sua percepção a plataforma Elgg apresentava características mais adequadas ao contexto docente do século XXI. Esse comentário sinaliza que professor 2 entendeu as funcionalidades da RSI. Ou seja, percebeu que as RSI podem proporcionar mais autonomia aos alunos, afinal esses podem partilhar informações da mesma forma que o professor, tornando a relação mais horizontal. Segundo Attwell (2007), as RSI têm colaborado para que os até então consumidores tornassem-se produtores, criando e compartilhando informações.

A cada semana o uso dos recursos da RSI foi se intensificando. Como a maioria não utilizava o twitter, a ferramenta "microblog" (o twitter na RSI) foi pouco utilizada nas duas primeiras semanas. A partir da percepção desse fato, no segundo encontro presencial foram comentadas as possibilidades dessa ferramenta, por meio da discussão de um texto. Essa ação tornou o microblog uma das ferramentas mais usadas. Por meio dessa, compartilham-se informações, parabenizam-se colegas, mandam-se recados, avisa-se de materiais postados em outras ferramentas da rede, entre outras finalidades.

O primeiro uso do recurso "arquivo", pelos professores, foi para postar os planejamentos anuais. Essa ação foi realizada por todos os professores com facilidade. A análise dos planejamentos orientou as atividades a serem desenvolvidas. Textos já haviam sido postados para discussão. A professora 5 destacou que essa possibilidade é importante para o trabalho colaborativo e que no Orkut, essa ação não é possível.

Duas semanas após o início da formação a professora 5 criou espontaneamente um "blog" contendo informações sobre temas que estavam sendo discutidos nos encontros e por meio da $\mathrm{RSI}^{11}$. Essa ação sinaliza que a mesma sabe usar o recurso, além de ressaltar a compreensão da filosofia de uma rede social no que se refere ao compartilhamento e discussão de informações. Antecedendo à criação do referido blog, vários comentários já haviam sido feitos nos blogs criados pela mediadora.

A primeira utilização da ferramenta "favoritos" foi realizada pelo professor 2 que socializou o link do currículo mínimo de Matemática da rede estadual. Na ocasião, esse recurso foi explicado para os demais professores. A partir de então, outros professores também utilizaram. No terceiro encontro, enquanto uma professora convidada apresentava o tema "Uso de dispositivos móveis na aprendizagem de Matemática", os professores socializavam links citados pela palestrante.

A ferramenta "wiki" foi apresentada no segundo encontro, todos os professores não a conheciam. Em momentos diversos, a partir do segundo encontro, os alunos socializavam oralmente situações nas quais estavam aplicando os conhecimentos construídos na formação T-PROIM nas suas práticas docentes. Sendo assim, a mediadora criou o primeiro wiki que é um espaço para registro das contribuições. Parte do texto da professora 6 resume as contribuições da formação e sinaliza um bom uso da ferramenta além de mostrar que o objetivo da formação está sendo alcançado:

Por estar participando desse grupo, me sinto mais segura para utilizar tecnologias. Até então não tinha utilizado e minha primeira experiência foi incentivada aqui. Foi uma atividade sobre poliedros utilizando o Poly. Falei em segurança, pois antes de trabalhar a atividade com os alunos posso compartilhá-la com os participantes do grupo, ouvir sugestões, experiências e até mesmo incentivo, como aconteceu quando mostrei a atividade sobre poliedros. Deu tudo certo e o resultado foi ótimo. Como professora iniciante ainda tenho muitas dúvidas, incertezas e insegurança e saber que posso dividi-las com pessoas do mesmo meio, e que tenho a quem recorrer tem me ajudado bastante. Até uma questão que não conseguia resolver, postei na rede e obtive resposta. Isso não é o máximo!

Foram criados dois "grupos de discussão", um para o ensino fundamental e outro para o ensino médio. Os tópicos de discussão no âmbito de cada grupo foram criados pelos professores, esse espaço foi usado para compartilhar dúvidas de conteúdos matemáticos, solicitar materiais e pedir sugestões para abordagem de algum conteúdo. 
De maneira geral, percebe-se que as atividades desenvolvidas nos encontros presenciais e por meio da RSI têm influenciado a prática docente dos professores participantes. A cada novo encontro ocorrem depoimentos de ações que envolvem o uso das TD com ótima receptividade dos alunos dos professores participantes da formação.

\section{Considerações Finais}

A análise das atividades realizadas na formação assim como das atitudes dos participantes sinalizaram que os recursos das RSI são fáceis de usar e contribuem para a interação entre professor e aluno e entre os alunos. A flexibilidade da formação $\mathrm{T}$ PROIM e da configuração de recursos da RSI pelos usuários foi considerada importante para o contexto educacional, pois permite atender particulares. A possibilidade de compartilhar informações diversas cria um espaço menos formal para contexto educacional. Este espaço pode servir como motivação para as atividades formais.

A partir da análise dos instrumentos de coleta de dados algumas ações futuras já foram planejadas, a saber: estudo e experimentação do sistema operacional Linux; instalação de softwares matemáticos no referido sistema; criação de blog para as escolas dos professores; criação de mapas conceituais; análise de recursos tecnológicos disponíveis na Internet para estudo de temas matemáticos; avaliação das atividades realizadas na formação e na prática docente dos professores participantes.

Pretende-se com a proposta de formação T-PROIM contribuir para que os professores expressem suas ideias, necessidades e experiências de modo a tornarem autores de recursos pedagógicos e construtores de práticas docentes inovadoras. Além de apontar caminhos para que os próprios professores trilhem seus caminhos.

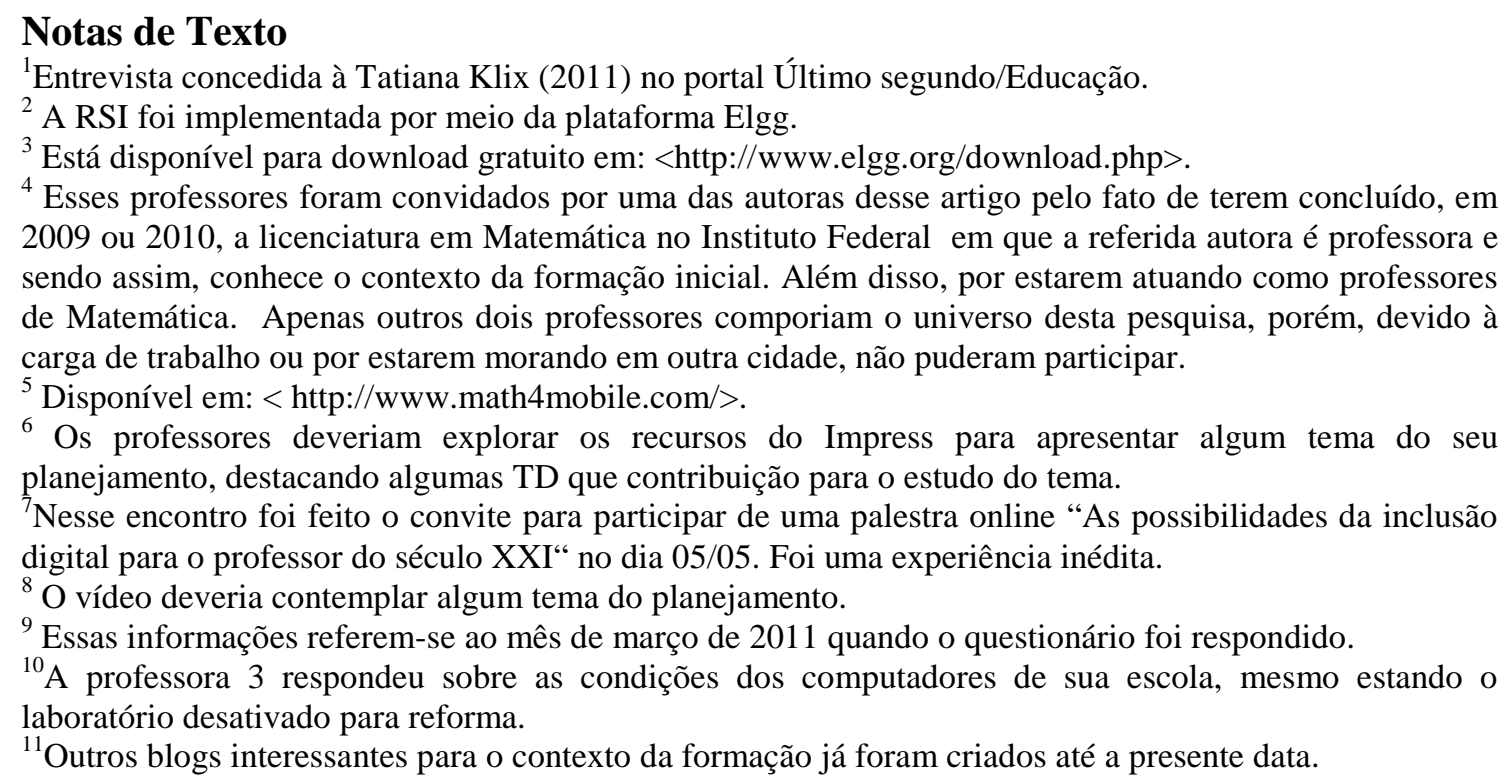

Referências Bibliográficas

ATTWELL, G. Personal Learning Environments - the future of eLearning? Elearningpaper, v.2, n. 1, Janeiro 2007. Disponível em: http://www.elearningpapers.eu/index.php?page $=$ doc\&doc_id $=8553 \& d o c \operatorname{lng}=6$. Acesso em 16. maio. 2011.

ATTWELL, G. Personal Learning Environments. Anais Primeiro Encontro Internacional de TIC e Educação - TicEDUCA2010. Lisboa-Portugal. Novembro 2010; Disponível em: <http://ticeduca.ie.ul.pt/resumos/pages/conferencias.html>. Acesso em: 16 maio. 2011.

BARCELOS, G. T.; PASSERINO, L. M.; BEHAR, P. A. Proposta de Formação para Integração das Tecnologias de Informação e Comunicação às Práticas Docentes de Professores de Matemática. In: CONGRESSO IBEROAMERICANO DE 
INFORMÁTICA EDUCATIVA (IE 2010), 1-3 dez. 2010, Santiago, Chile. Actas ... Santiago, Chile, 2010.

BRASIL, Decreto $\mathbf{n}^{\mathbf{0}} \mathbf{6 . 3 0 0}$, de 12 de dezembro de 2007, publicado no Diário Oficial da União de 13/12/2007, p. 3, 2007b. Disponível em: <http://www.planalto.gov.br/ccivil_03/_Ato2007-2010/2007/Decreto/D6300.htm> Acesso em 21 abr. 2011.

CLARK, L. A.; ROBERTS, S. J. Employer's Use of Social Networking Sites: A Socially Irresponsible Practice. Journal of Business Ethics v.95, p. 507-525, 2010.

COSTA, F. (Coord.). Competências TIC: estudo de Implementação, v.1. Lisboa: Gepe/ME (Gabinete de Estatística e Planejamento da Educação), 2008.

ELGG, Introducing a powerful open source social networking engine. Disponível em: 〈http://elgg.org/index.php>. Acesso em: 17 abr. 2011.

FVC- Fundação Vitor Civita. O uso dos computadores e da internet nas escolas públicas de capitais brasileiras, 2009. Disponível em: <www.fvc.org.br/estudos>. Acesso em: 03 mar. 2011.

GRAHAM, C. R. Blended learning systems definition, current trends, and future directions. In: BONK, C. J.; GRAHAM, C. R.; CROSS, J.; MOORE M.G. (Ed.). The handbook of blended learning: global perspectives, local designs. São Francisco: Pfeiffer Publishing, 2005, p. 3-21.

IMBERNÓN, F. Formação Continuada de Professores. Tradução de Juliana dos Santos Padilha. Porto Alegre: Artmed, 2010.

KLIX, T. Educador quer Redes Sociais no Currículo Escolar. Último Segundo Educação. $2011 \quad$ Disponível em:< http://ultimosegundo.ig.com.br/educacao/educador\%20quer\%20redes\%20sociais\%20no \%20curriculo\%20escolar/n1238187320827.html> Acesso em: 11 abr. 2011.

JONES, Q.Virtual-Communities, Virtual Settlements \& Cyber-Archaelogy: a theoretical Outline. Journal of Computer-Mediated Communication. v. 3., n. 3. Dez. 1997. Disponível em:<http://jcmc.indiana.edu/vol3/issue3/jones.html >.Acessoem:27mai.2011. LINCKELS, S. et al. Teaching with information and communication technologies: preliminary results of a large scale survey. In: SIGUCCS Fall Conference, 2009, St. Louis, Missouri. Proceedings .... New York, USA: ACM, 2009. p. 157-162

MILLIGAN, C.; BEAUVOIR, P.; JOHNSON, M.; SHARPLES, P.; WILSON, S.; \& LIBER, O. Developing a reference model to describe the personal learning environment. Proceedings First European Conference on Technology Enhanced Learning, EC-TEL 2006. Creta, Grécia. Berlin / Heidelberg: Springer-Verlag.

MOTA, J. Personal Learning Environments: contributos para uma discussão do conceito. Educação, Formação \& Tecnologias, v.2, n.2, p. 5-21, Novembro de 2009.

RECUERO, R. Redes Sociais na Internet. Porto Alegre: Sulina, 2009.

TARDIF, M. Saberes docentes e formação profissional. 8.ed. Tradução de Francisco Pereira. Petrópolis-RJ: Vozes, 2007.

UNESCO. Coleção Padrões de Competência em TIC para Professores: Módulos de Padrões de Competências. Tradução de Cláudia Bentes David.Brasília: UNESCO, 2009. VOSGERAU, D. S. A. R.; ENDLICH, E.; PINTO, A. M.; BOLSI, C. O projeto Cri@tividade: a formação em serviço para integração das TIC. In: BEHRENS M. A.; ENS R. T.; VOSGERAU D. S. R. (Org.). Discutindo a educação na dimensão da práxis. v. 1 Curitiba: Cahmpagnat, 2007, p.165-182.

VYGOTSKY, L. S. A formação social da mente: o desenvolvimento dos processos psicológicos superiores. 7. ed. São Paulo: Martins Fontes, 2007.

WILSON, S. Future VLE - The Visual Version. Scott's Workblog, 2005. Disponível em: <http://zope.cetis.ac.uk/members/scott/blogview?entry=20050125170206>. Acesso em: 05 jan. 2011. 